\title{
The "false-positive" conundrum: IgA reference level overestimates the seroprevalence of antibodies to SARS-CoV-2
}

\author{
Bruno Caramelli ${ }^{1}$, Maria C \\ Escalante-Rojas ${ }^{1}$, Hiteshi \\ K C Chauhan², Rinaldo \\ F Siciliano ${ }^{1}$, Marcio S \\ Bittencourt ${ }^{3}$, Antonio C \\ Micelli ${ }^{4}$
${ }^{1}$ InCor, University of São Paulo, São Paulo, Brazil
${ }^{2}$ Department of Cardiology, Fortis Hospital, Mohali, India
${ }^{3}$ Hospital Israelita Albert Einstein, Sao Paulo, Brazil; Faculdade Israelita de Ciências da Saúde Albert Einstein, São Paulo, Brazil; Center for Clinical and Epidemiological Research, University Hospital, University of Sao Paulo, Sao Paulo, Brazil
${ }^{4}$ Hospital das Clínicas, FMUSP, São Paulo, Brazil

\begin{abstract}
Background On 12 June 2020, Brazil reached the second position worldwide in the number of COVID-19 cases. Authorities increased the number of tests performed, including the identification of antibodies to SARS-CoV-2 (IgG, IgA, and $\operatorname{IgM}$ ). There was an overflooding of the market with several tests, and the presence of possible false-positive results became a challenge. The purpose of this study was to describe the seroprevalence and immunoglobulin blood levels in a group of asymptomatic individuals using the reference levels provided by the manufacturer.

Methods Levels of IgG and IgA antibodies to SARS-CoV-2 were determined in blood serum by the same ELISA (enzyme-linked immunoassay) test. Patients must be free of symptoms.

Results: From 20 to 22 May 2020, 938 individuals were tested. There were 441 $(47 \%)$ men, age 53 years (interquartile range $(I Q R)=39-63.2)$. The sample included $335(35.7 \%)$ subjects aged $\geq 60$ years old. Subjects with a positive test were 54 (5.8\%) for IgG and 96 (10.2\%) for IgA and 42 (4.5\%) for both $\operatorname{IgG}$ and IgA. The prevalence of $\operatorname{IgG}$ and IgA positive test was not different in men and women and not different in individuals under 60 and over 60 years of age. Conversely, analysing only individuals with positive tests, the levels of $\operatorname{Ig} G$ in positive subjects were significantly higher than those with an IgA positive test, 3.00 (IQR = 1.68-5.65), and 1.95 ( $\mathrm{IQR}=1.40-3.38$ ), respectively; $P=0.017$. Additionally, individuals with isolat-ed IgA positive tests had significantly lower levels of IgA than those with both IgA and IgG positive tests: $1.95(\mathrm{IQR}=1.60-2.40)$ and $3.15(\mathrm{IQR}=2.20-3.90)$, respec-tively, $P=$ 0.005 . These latter data suggest that IgA shows a deviation of the distri-bution to the left in comparison to IgG distribution data. Indeed, many subjects reported as IgA positive had immunoglobulin levels slightly elevated.
\end{abstract}

Conclusions In conclusion, we strongly suggest caution in the interpretation of IgA test results. This recommendation is more important for those with positive IgA just above the reference level.

The first case of severe acute respiratory syndrome coronavirus 2 (SARS-CoV-2) infection in Brazil was reported in São Paulo on 26 February 2020. On 12 March 2020, the first death related to the disease was confirmed, and on 13 March 2020, the first cases linked to community transmission were reported in Rio and São Paulo, the biggest cities in the Country. There was a rapid progression in the number of cases followed by subsequent requirement for intensive care support in proportions never experienced before. Exceptional efforts were made by the health authorities to cope with this monumental escalation of a snowballing pandemic. However, the initiatives and strategies deployed were not uniform across a Country with continental dimensions [1-5]. 
Despite strong recommendations, social distancing rates remained below desirable levels for most of the time period. Two possible consequences of the aforementioned were: a) intensive care units' occupancy remained below $80 \%$, most of the time and in majority of the cities of the Country, especially São Paulo and b) the number of new cases and the number of deaths reached either a stable plateau or showed a worrisome growth in some regions [6].

On 1 June 2020, in São Paulo, health authorities implemented a stepwise system to authorize economic activities to resume [7]. The main criteria included the average rate of intensive care units designated exclusively for SARS-CoV-2 patients, the number of new hospital admissions, and the death rate. On 12 June 2020, Brazil reached the dubious and worrisome distinction of attaining the second position Worldwide in the number of COVID-19 cases. In response, authorities, individuals on own initiative or requested by employers, clubs or airlines, increased the number of tests performed, both for the diagnosis of SARS-CoV-2 infection (molecular or PCR test) and the diagnosis of past infection in symptomatic and asymptomatic individuals through the identification of antibodies to SARS-CoV-2, ie, the determination of seroprevalence of IgG, IgA, and IgM [8-10].

Historically, seroprevalence data offers valuable information related to the development and progression of an epidemic outbreak [11]. However, the unique and largely unknown immunological response to SARS-CoV-2 limits the full epidemiological and clinical use of the test results [12-15]. Moreover, the determination of seroprevalence has exposed several caveats related to the use of qualitative instead of quantitative tests, the sum of different immunoglobin classes as a unique seroprevalence, and the presence of false-negative and false-positive results. Adding fuel to this uncertainty is the overflooding of the market with several tests, which has led to the unfortunate sequalae of pitting caregivers and patients on opposite ends of a divisive spectrum, arguing about test results that probably still require reference data. In our clinical practice, it has become increasingly common to field requests for an interpretation of serology testing from patients and friends. We observed that IgA results are more frequently positive, even in the absence of past clinical symptoms.

To test our hypothesis, we sought to analyze data obtained, at the end of May 2020, from a convenience sample of asymptomatic individuals analyzed by the same commercial diagnostic laboratory test to estimate the seroprevalence by age and gender, using the reference levels provided by the manufacturer.

\section{METHODS}

This is a time-sensitive cross-sectional study that involved members from an upper-class social and sports club in São Paulo, Brazil. Blood samples were collected from May 20-22, 2020, in the Club's garage, a vast open space that allowed social distancing. Levels of IgG and IgA antibodies to SARS-CoV-2 were determined in blood serum by ELISA technology (Anti-SARS-CoV-2 IgG and IgA, EUROIMMUN BRASIL MEDICINA DIAGNOSTICA LTDA), and were performed in the same laboratory [7]. The cutoff level provided by the manufacturer for a positive test was an index greater than 1.1 for both IgG and IgA antibodies. Patients with fever, dyspnea, cough, or other symptoms related to active disease were not authorized by the club board to come and are not represented in this group. Demographic data was obtained from all patients.

Descriptive data are presented as absolute values, percentages, median, and interval interquartile range (IQR). For the comparisons we assumed non normal distribution and used nonparametric tests: Mann-Whitney test (Tabular results, Unpaired) for continuous variables, Pearson $\chi^{2}$ test with Yates' continuity for categorical variables and odds-ratio (OR), with 95\% confidence interval (CI), calculated by Baptista-Pike method and performed using GraphPad Prism version 8.4.3 for Windows (GraphPad Software, San Diego, California USA, www.graphpad.com). Frequency distribution of different IgA and IgG levels was also analyzed and compared.

\section{RESULTS}

From May 20 to 22, 938 individuals were tested. There were 441 (47\%) men and 497 women, age 53 years $(\mathrm{IQR}=39.0-63.2)$. The sample included 335 (35.7\%) individuals aged 60 or more years old. Individuals with a positive test (index $\geq 1.1$ ) were 54 (5.8\%) for IgG and 96 (10.2\%) for IgA, and 42 (4.5\%) for both $\operatorname{IgG}$ and IgA (Figure 1).

The prevalence of positive tests by age and gender groups, IgG, and IgA levels are depicted in Table 1 and Table 2. The prevalence of $\operatorname{IgG}$ and $\operatorname{IgA}$ positive test was not different in men and women $(\mathrm{OR}=1.14$, 95\% CI $=0.65-1.97$ for $\operatorname{IgG}$ and $\mathrm{OR}=1.04,95 \% \mathrm{CI}=0.68-1.59$ for $\mathrm{IgA} ; \mathrm{P}=0.937$ ) and not different in individuals un-der 60 and 60 years old $(O R=1.12,95 \% C I=0.63-2.00$, for $\operatorname{Ig} G$ and $O R=0.87,95 \% C I=0.57-1.35, P=0.619)$. 


\section{Serology for COVID-19 (IgG / /gA)}

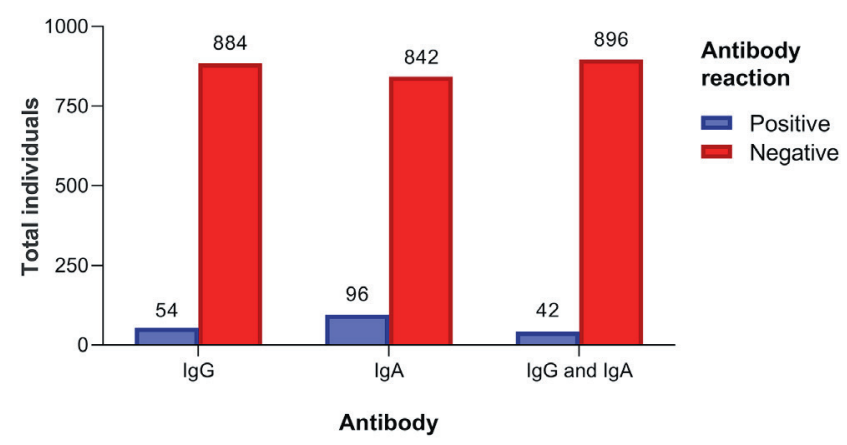

Figure 1. Distribution of total subjects by antibody, in the cohort of 938 individuals.
Of note, the median IgG and IgA levels were nearly10-fold greater in individuals with a positive than in those with negative test (Table 1 and Table 2)

The frequency distribution of different IgA and IgG levels is shown in Figure 2. Remarkably, visual analysis of IgA demonstrates an apparent deviation of the distribution to the left in comparison to IgG distribution data. Conversely, analyzing only individuals with positive tests, the levels of IgG in individual with a positive test were significantly higher than in those with an IgA positive test, $3(\mathrm{IQR}=1.68-5.65)$ vs 1.95 (IQR $=1.40-3.38$ ). Additionally, individuals with isolated IgA positive test showed significant lower levels of IgA than those with both $\operatorname{IgA}$ and $\operatorname{Ig} G$ positive tests: 1.95 (1.60$2.40)$ vs $3.15(2.20-3.90)$.

Table 1. Demographic characteristics in IgG positive and negative subjects

\begin{tabular}{|c|c|c|c|c|c|}
\hline & ALL IGG, $N=938, N(\%)$ & IGG+, N = 54, N (\%) & IGG -, N = 884, N (\%) & OR (95\%Cl) & P-VALUE \\
\hline \multicolumn{6}{|l|}{ Gender (n, \%): } \\
\hline Male & $441(47.01 \%)$ & $27(50 \%)$ & $414(46.83 \%)$ & $1.14(0.65-1.97)$ & 0.755 \\
\hline Female & $497(52.99 \%)$ & $27(50 \%)$ & $470(53.17 \%)$ & & \\
\hline \multicolumn{6}{|l|}{ Age (n, \%) } \\
\hline Age $<60$ & $603(64.29 \%)$ & $36(66.67 \%)$ & $567(64.14 \%)$ & $1.12(0.63-2.00)$ & 0.818 \\
\hline Age $\geq 60$ & $335(35.71 \%)$ & $18(33.33 \%)$ & $317(35.86 \%)$ & & \\
\hline Age, median (IQR) & $53(39.00-63.25)$ & $48.5(32.75-66.50)$ & $53(39.00-63.00)$ & & 0.563 \\
\hline Ig level, median (IQR) & $0.30(0.20-0.40)$ & $3(1.68-5.65)$ & $0.30(0.20-0.30)$ & & $<0.001$ \\
\hline
\end{tabular}

$\mathrm{OR}$ - odds ratio, $\mathrm{CI}$ - confidence interval, IQR - interquartile range

Table 2. Demographic characteristics in IgA positive and negative subjects*

\begin{tabular}{|c|c|c|c|c|c|}
\hline & ALL IGA, N = 938, N (\%) & IGA+, N = 96, N (\%) & IGA-, $N=842, N(\%)$ & OR $(95 \% \mathrm{Cl})$ & P-VALUE \\
\hline \multicolumn{6}{|l|}{ Gender (n, \%): } \\
\hline Male & $441(47.01 \%)$ & $46(47.92 \%)$ & $395(46.91 \%)$ & $1.04(0.68-1.59)$ & 0.937 \\
\hline Female & $497(52.99 \%)$ & $50(52.08 \%)$ & 447 (53.09\%) & & \\
\hline \multicolumn{6}{|l|}{ Age (years; n, \%) } \\
\hline Age $<60$ & $603(64.29 \%)$ & $59(61.46 \%)$ & $544(64.61 \%)$ & $0.87(0.57-1.35)$ & 0.619 \\
\hline Age $\geq 60$ & $335(35.71 \%)$ & $37(38.54 \%)$ & $298(35.39 \%)$ & & \\
\hline Age, median (IQR) & $53(39.00-63.25)$ & $52.50(38.25-64.00)$ & $53(39.00-63.00)$ & & 0.688 \\
\hline Ig level, median (IQR) & $0.30(0.20-0.50)$ & $1.95(1.40-3.38)$ & $0.20(0.20-0.40)$ & & $<0.001$ \\
\hline
\end{tabular}

$\mathrm{OR}$ - odds ratio, $\mathrm{CI}$ - confidence interval, IQR - interquartile range

\section{Distribution of IgA levels according to IgG levels in subjects with positive $\lg A$ tests}

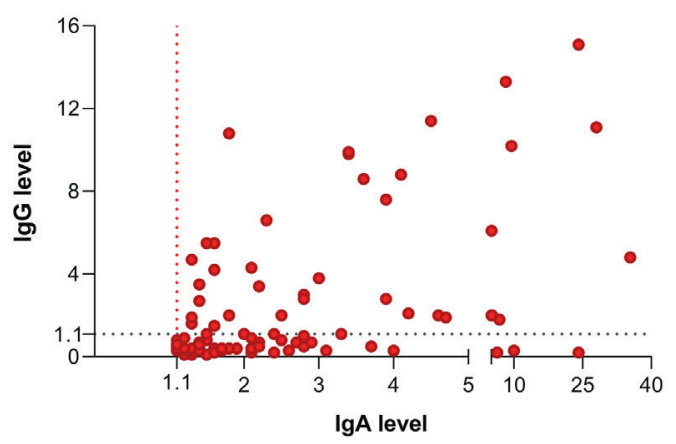

Distribution of IgG levels according to IgA levels in subjects with positive IgG tests

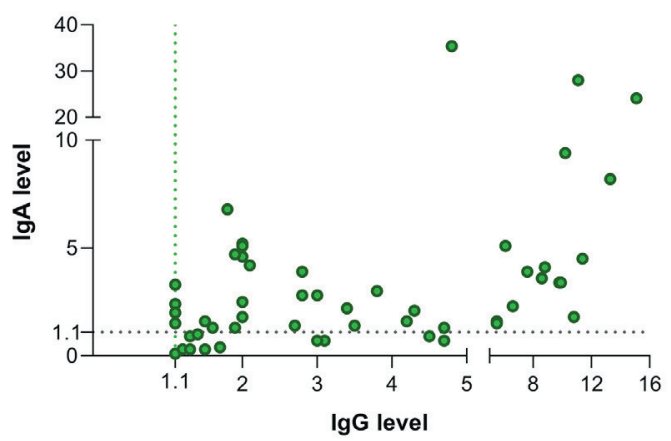

Figure 2. Frequency distribution of positive subjects by antibody IgG and IgA. 


\section{DISCUSSION}

We report a cross-sectional study of qualitative (seroprevalence) and quantitative (serum levels of IgA and IgG) antibodies to SARS-CoV-2 in a cohort of 938 free-of-symptoms subjects in São Paulo, Brazil, at the end of May 2020. Previous reports in the literature privileged the analyzes $\&$ interpretation of seroprevalence (qualitative aspects) and longitudinal follow-up data [13-16]. The quality and strength of the information provided by antibody tests has been strongly criticized [17].

The present study was elaborated as a response to recurring clinical practice dilemma, ie, frequent requests for interpretation of results of serological tests by patients with positive results, especially for IgA. Considering the reference levels provided by the manufacturer, seroprevalence results were 5.8 and 10.2 for $\operatorname{Ig} G$ and $\operatorname{IgA}$, respectively. In our cohort, seroprevalence was not different in men and women but was higher in subjects less than 60 years old. This finding is similar to a recent publication from the United States. [18]

On the other hand, the quantitative data showed that the frequency distribution of Ig levels in positive subjects with positive results is quite different between IgG and IgA. Notably, IgA levels distribution in subjects with a positive test deviates to the left in comparison to IgG distribution data. This phenomenon indicates that many subjects reported as IgA positive have immunoglobulin levels just above the 1.1 reference level. The explanation for this finding is not provided by this or previous studies, but it is not possible to exclude the presence of false-positive results or a misleading reference value. The finding of higher immunoglobulin levels in subjects tested positive for IgG than those for IgA and the lower IgA levels in subjects tested positive only for IgA than those positive for both IgA and IgG also suggest a false-positive result or a recent infection. Positive results always create worries and a tense vibe for patients and their families. Health care systems and health authorities may get overburdened with strategizing as to the best policy towards these asymptomatic individuals.

To the present moment, there is no precise information regarding the clinical or epidemiological relevance of the almost 2-fold increase in the IgA in comparison to $\operatorname{Ig} G$ levels. Considering the finding of this study, ie, that many subjects reported as IgA positive have immunoglobulin levels slightly elevated, we strongly suggest caution in the interpretation of IgA test results. This recommendation is more important for those with positive IgA just above the reference level. These individuals should go in for a repeat comprehensive evaluation and health care providers should not base their decision on this analysis. Confirmation of the hypothesis generated by these data needs future studies and could allow additional interpretation of them.

Acknowledgements: The authors would like to thank the President of the Club Athletico Paulistano and Drs Fernando Behn Aguiar and Arnaldo Lombardi Junior for help in collecting data.

Funding: Bruno Caramelli has a Grant (304352/2016-0) from the National Council for Scientific and Technological Development (CNPQ).

Authorship contributions: BC and HKCC discussed the initial idea, MCE-R organized data collection, analyzed results and performed statistical analysis, ACM organized data collection. All author participated in the discussion and approved the final version of the manuscript.

Competing interests: The authors completed the ICMJE Unified Competing Interest form (available upon request from the corresponding author), and declare no conflicts of interest.
}

1 Burki T. COVID-19 in Latin America. Lancet Infect Dis. 2020;20:547-8. Medline:32311323 doi:10.1016/S1473-3099(20)30303-0

2 Antunes BBP, Peres IT, Baião FA, Ranzani OT, Bastos LDSL, Silva AABD, et al. Progression of confirmed COVID-19 cases after the implementation of control measures. Rev Bras Ter Intensiva. 2020;32:213-23. Medline:32667447 doi:10.5935/0103507X.20200028

3 Baqui P, Bica I, Marra V, Ari E, van der Schaar M. Ethnic and regional variations in hospital mortality from COVID-19 in Brazil: a cross-sectional observational study. Lancet Glob Health. 2020;8:e1018-26. Medline:32622400 doi:10.1016/S2214109X(20)30285-0

4 Corrêa PRL, Ishitani LH, Abreu DMX, Teixeira RA, Marinho F, França EB. The importance of surveillance in cases of and mortality from the COVID-19 epidemic in Belo Horizonte, Brazil, 2020. Rev Bras Epidemiol. 2020;23:e200061. Medline:32785450

5 Cavalcante JR, Cardoso-Dos-Santos AC, Bremm JM, Lobo AP, Macário EM, Oliveira WK. COVID-19 in Brazil: evolution of the epidemic up until epidemiological week 20 of 2020. Epidemiol Serv Saude. 2020;29:e2020376. Medline:32785434

6 Bloomberg. WHO Says Brazil's Covid-19 Curve Has Plateaued. Available: https:/www.bloomberg.com/news/articles/2020-07-17/ who-says-brazil-s-covid-19-curve-has-plateaued. Accessed: 13 August 2020.

7 Agência Brasil. São Paulo state unveils gradual economic resumption plan. Available: https://agenciabrasil.ebc.com.br/en/economia/noticia/2020-05/sao-paulo-state-unveils-gradual-economic-resumption-plan. Accessed: 13 August 2020. 
8 Amorim Filho L, Szwarcwald CL, Mateos SOG, Leon ACMP, Medronho RA, Veloso VG, et al. Seroprevalence of anti-SARSCoV-2 among blood donors in Rio de Janeiro, Brazil. Rev Saude Publica. 2020;54:69. Medline:32638883 doi:10.11606/s15188787.2020054002643

9 Silveira MF, Barros AJD, Horta BL, Pellanda LC, Victora GD, Dellagostin AO, et al. Population-based surveys of antibodies against SARS-CoV-2 in Southern Brazil. Nat Med. 2020;26:1196-9. Medline:32641783 doi:10.1038/s41591-020-0992-3

10 Castro R, Luz PM, Wakimoto MD, Veloso VG, Grinsztejn B, Perazzo H. COVID-19: a meta-analysis of diagnostic test accuracy of commercial assays registered in Brazil. Braz J Infect Dis. 2020;24:180-7. Medline:32330437 doi:10.1016/j.bjid.2020.04.003

11 Vieira MADCES, Vieira CPB, Borba AS, Melo MCC, Oliveira MS, Melo RM, et al. Sequential serological surveys in the early stages of the coronavirus disease epidemic: limitations and perspectives. Rev Soc Bras Med Trop. 2020;53:e20200351. Medline:32638891 doi:10.1590/0037-8682-0351-2020

12 Serrano MM, Rodríguez DN, Palop NT, Arenas RO, Córdoba MM, Mochón MDO, et al. Comparison of commercial lateral flow immunoassays and ELISA for SARS-CoV-2 antibody detection. J Clin Virol. 2020;129:104529. Medline:32659710 doi:10.1016/j.jcv.2020.104529

13 Klein SL, Pekosz A, Park HS, Ursin RL, Shapiro JR, Benner SE, et al. Sex, age, and hospitalization drive antibody responses in a COVID-19 convalescent plasma donor population. J Clin Invest. 2020;130:6141-50. Medline:32764200 doi:10.1172/ JCI142004

14 Deeks JJ, Dinnes J, Takwoingi Y, Davenport C, Spijker R, Taylor-Phillips S, et al. Antibody tests for identification of current and past infection with SARS-CoV-2. Cochrane Database Syst Rev. 2020;6:CD013652. Medline:32584464

15 Lucas C, Wong P, Klein J, Castro TBR, Silva J, Sundaram M, et al. Longitudinal analyses reveal immunological misfiring in severe COVID-19. Nature. 2020;584:463-9. Medline:32717743 doi:10.1038/s41586-020-2588-y

16 Kirkcaldy RD, King BA, Brooks JT. COVID-19 and Postinfection Immunity: Limited Evidence, Many Remaining Questions. JAMA. 2020;323:2245-6. Medline:32391855 doi:10.1001/jama.2020.7869

17 Scientific American. Coronavirus Antibody Tests Have a Mathematical Pitfall. Available: https://www.scientificamerican.com/ article/coronavirus-antibody-tests-have-a-mathematical-pitfall/. Accessed: 13 August 2020.

18 Havers FP, Reed C, Lim T, Montgomery JM, Klena JD, Hall AJ, et al. Seroprevalence of antibodies to SARS-CoV2 in 10 sites in the United States, March 23-May 12, 2020. JAMA Intern Med. Online ahead of print. Medline:32692365 